\title{
COASTAL FLOODING, WAVE OVERTOPPING AND BEACH GROUNDWATER INTERACTIONS
}

\author{
Timu Gallien, University of California, Los Angeles, tgallien@ucla.edu \\ Marie-Pierre Delisle, University of California, Los Angeles, mpdelisle@ucla.edu
}

\begin{abstract}
INTRODUCTION
Coastal flooding is a significant humanitarian and socioeconomic hazard (e.g., Nicholls, 2010). Global mean sea levels are expected to rise over the coming century and mean higher high water (MHHW) and mean high water (MHW), peak levels that drive coastal flooding, show upward trends in many locations (Mawdsley et al., 2015). Significant coastal flooding will occur by 2050 (e.g., Tebaldi et al., 2012; Sweet and Park, 2014). Wave overtopping is primary driver of coastal flooding. Lowlying urbanized sand spits, backed by an estuary are particularly vulnerable to sea level rise. Recent field observations suggest distinct feedbacks between wave overtopping, beach groundwater levels and backshore vulnerability.
\end{abstract}

\section{METHODS}

Beach groundwater and wave runup measurements were collected at Cardiff State Beach located in San Diego County, California. ADCPs deployed offshore in $\sim 8 \mathrm{~m}$ depth recorded waves. Multiple beach and bathymetry surveys were conducted during the experiment on scheduled and a storm-by-storm basis. Backshore flood extent was measured using real time kinematic surveys using Scripps Orbit and Permanent Array (SOPAC) SIO5 base station corrections (http://sopac.ucsd.edu/).

An array of 16 pressure sensors measuring at $2 \mathrm{~Hz}$ was deployed at Cardiff State Beach (Figure 1) along a transect from the estuary (PC1) through the beach ending at approximately mean lower low water (PC16) with four pressure sensors (PC9-PC12) in alternative alongshore positions. Multiple sensors were paired and collocated, i.e., one transducer placed below the water table and the other $\sim 50 \mathrm{~cm}$ below sand level to simultaneously record beach groundwater levels and overtopping, respectively.

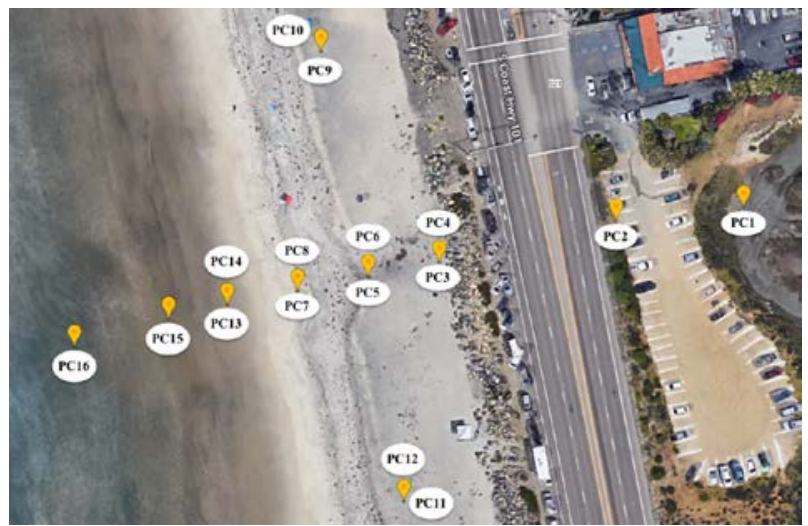

Figure 1, Pressure sensor array at Cardiff State Beach

Preliminary numerical simulations are being conducted using XBeach (Roelvink et al., 2009) and Pflotran (Lictner et al., 2013) to investigate feedbacks between wave runup beach groundwater and backshore flooding.

\section{RESULTS \& DISCUSSION}

Figure 2 shows four days of energetic waves and high tides. Overtopping (PC4, black solid line) and backshore flooding peaked approximately one hour after oceanic high tide and is in phase with beach groundwater levels. Flooding is often presumed to peak with the tide, however maximum backshore vulnerability may significantly lag ocean tide peak.

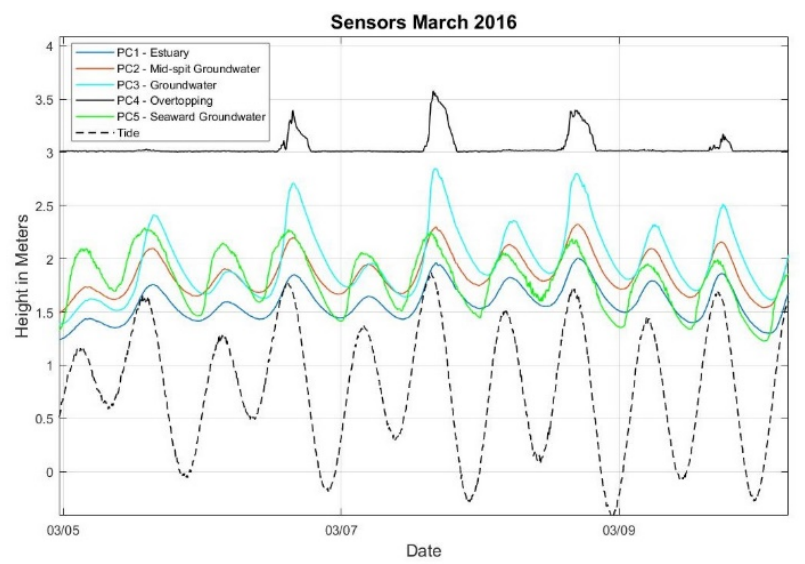

Figure 2, Pressure sensor data

\section{REFERENCES}

Lichtner, Hammond, Lu, Karra, Bisht, Andre, Mills and Kumar (2013). PFLOTRAN user manual. Technical report, various US National Laboratories.

Mawdsley, Haigh, Wells, (2015). Global secular changes in different high water, low water and range levels. Earth's Future, 3, 66-81.

Nicholls (2010). Impacts of and responses to sea-level rise. Understanding Sea-Level Rise and Variability. Eds J.A. Church, P.L. Woodworth, T. Aarup, and W.W. Wilson, Wiley-Blackwell, pp 17-51.

Roelvink, Reniers, Van Dongeren, van Thiel de Vries, McCall, Lescinski, (2009). Modelling storm impacts on beaches, dunes and barrier islands. Coastal Engineering, 56, 1133-1152.

Sweet and Park (2014). From the extreme to the mean: Acceleration and tipping points of coastal inundation from sea level rise. Earth's Future, 2, 1-11.

Tebaldi, Strauss, Zervas, (2012). Modelling sea level rise impacts on storm surges along US coasts. Environmental Research Letters 7, $12 \mathrm{pp}$. 